\title{
Pancreatic fusocellular sarcoma. The importance of endoscopic ultrasound-guided fine needle aspiration in the differential diagnosis of solid pancreatic tumors
}

\author{
J. Iglesias García ${ }^{1,2}$, R. Ferreiro ${ }^{1,2}$, J. Lariño Noia ${ }^{1,2}$, I. Abdulkader ${ }^{3}$, M. Álvarez del Castillo ${ }^{1,2}$, \\ B. Cigarrán ${ }^{2,4}$, J. Forteza Vila ${ }^{3}$ and J. E. Domínguez Muñoz ${ }^{1,2}$
}

${ }^{\prime}$ Gastroenterology Department. ${ }^{2}$ Foundation for Research in Digestive Diseases, and ${ }^{3}$ Pathology Department. University Hospital. Santiago de Compostela. A Coruña, Spain. ${ }^{4}$ Internal Medicine Department. Hospital Virxe da Xunqueira de Cee. A Coruña, Spain

\begin{abstract}
In the presence of a pancreatic tumor, the main diagnostic problem is to determine the benign o malignant nature of the lesion, and then to evaluate its resectability. A preoperative biopsy was usually rejected based on the fact that negative results do not exclude malignancy, that such biopsy may hamper the possibility of curative surgery because of potential seeding along the biopsy's trajectory, that surgical morbidity and mortality are low, and also because of the high diagnostic sensitivity of the various imaging techniques. Biopsy for solid pancreatic tumors was limited to irresectable tumors, and isolated cases with suspicion of tuberculosis, lymphoma or neuroendocrine tumors. Nowadays the performance of a pancreatic biopsy is becoming essential for the correct management of solid lesions, and is useful not only to establish malignancy, but also for a better knowledge of all kind of pathologies and, thus, for better therapeutic management. In this context, endoscopic ultrasound (EUS)-guided fine-needle aspiration (FNA) has proven a safe technique with a low rate of complications and a diagnostic accuracy superior to other procedures, this being considered the method of choice for the study of solid pancreatic lesions. An illustrative example is the case we report in this article -a patient diagnosed of a solid, locally advanced-stage pancreatic tumor with imaging techniques (abdominal ultrasounds and EUS) under EUS-guided FNA; the procedure could establish a final diagnosis of pancreatic fusocellular sarcoma.
\end{abstract}

Key words: Endoscopic ultrasounds. Fine-needle aspiration. Pancreatic tumors. Fusocellular sarcoma.

Received: 14-01-09.

Accepted: 22-01-09.

Correspondence: Julio Iglesias-García. Servicio de Aparato Digestivo. Fundación para la Investigación en Enfermedades del Aparato Digestivo (FIENAD). Hospital Universitario de Santiago de Compostela. C/ Choupana, s/n. 15706 Santiago de Compostela. A Coruña, Spain. e-mail: julioiglesiasgarcia@hotmail.es
Iglesias García J, Ferreiro R, Lariño Noia J, Abdulkader I, Álvarez del Castillo M, Cigarrán2 B, Forteza Vila J, Domínguez Muñoz. JE. Pancreatic fusocellular sarcoma. The importance of endoscopic ultrasound-guided fine needle aspiration in the differential diagnosis of solid pancreatic tumors. Rev Esp Enferm Dig 2009; 101: 498-504.

\section{INTRODUCTION}

Endoscopic ultrasounds (EUS) has become an essential tool for the study of pancreatic diseases, and is considered nowadays the procedure of choice for the diagnosis and staging of chronic pancreatitis and of both solid and cystic pancreatic tumors $(1,2)$.

The possibility to perform a real-time punction guided by EUS is an essential advance in the management of these patients, showing a high diagnostic accuracy (3-5) with a low rate of complications (6). In fact, indications presently accepted for the performance of pancreatic punction/biopsy include -besides cyto-histological confirmation for unresectable tumors eligible for oncological treatment, the differential diagnosis between chronic pancreatitis and pancreatic cancer, the preoperative diagnosis of pancreatic tumors, and suspicion of other pancreatic tumors, including neuroendocrine tumors, lymphomas, and pancreatic tuberculosis $(7,8)$.

\section{CASE REPORT}

We report the case of a 73-year-old with noninsulindependent diabetes mellitus, and a history of renal lithia- 
sis and prostate cancer (Gleason 7), under treatment with radiotherapy and hormone therapy. The patient was first admitted to the Emergency Department submitted by his general practitioner due to obstructive jaundice with choluria and acholia. The patient also had a general syndrome associated to weight loss $(20 \mathrm{~kg}$ over the last few months) and sustained hyperglycemia. During hospitalization we confirmed the presence of high bilirubin levels $(6.8 \mathrm{~g} / \mathrm{dL})$ and hypertransaminasemia (AST $101 \mathrm{U} / \mathrm{L}$, ALT $123 \mathrm{U} / \mathrm{L}$ ) with cholestasis (GGT $336 \mathrm{U} / \mathrm{L}$, alkaline phosphatase $1079 \mathrm{U} / \mathrm{L}$ ). The remaining blood parameters were normal. An abdominal ultrasonogram was performed, which detected the presence of a big heterogeneous pancreatic mass measuring $6.2 \times 5.8 \times 6.4 \mathrm{~cm}$, compatible with a malignant pancreatic tumor; it also identified malignant retroperitoneal and liver infiltration with minimal ascites around the liver and spleen, as well as a moderate focal enlargement of the bladder. The exam also described the presence of a dilated intrahepatic bile tree and common bile duct, and an enlarged gallbladder with microlithiasis. With the suspicion of pancreatic adenocarcinoma we performed EUS using a linear probe (PENTAX EG-3870UTK), and confirmed the presence of a very big hypoechoic and irregular lesion in the head of the pancreas -fusiform in shape, extending to the neck of the pancreas (Fig. 1), infiltrating the common bile duct, portal vein, splenic vein, superior mesenteric vein and confluence (with a marked alteration in the Doppler assessment) (Fig. 2), hepatic artery and superior mesenteric artery, as well as duodenal wall. We could also iden-

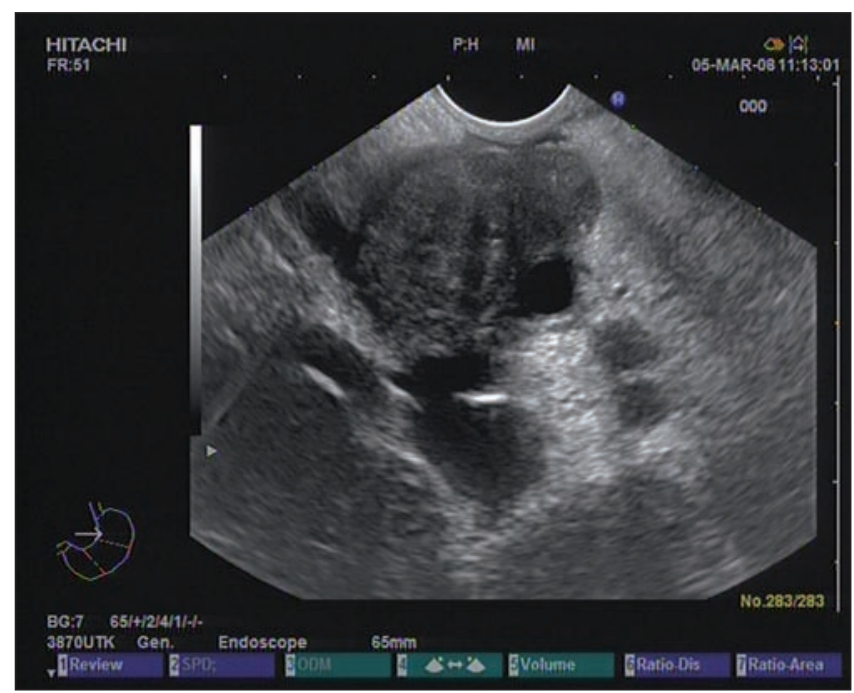

Fig. 1. EUS image demonstrating a big irregular, hypoechoic, and fusiform lesion located at the head of the pancreas, with extension to the pancreatic neck, infiltrating the confluence, and the duodenal wall. Imagen por ultrasonografía endoscópica que muestra una gran lesión a nivel de cabeza de páncreas, de predominio hipoecoico, con morfología fusiforme, extendiéndose hacia cuello pancreático, irregular, muy infiltrante, afectando la confluencia epleno-porto-mesentérica y la pared duodenal.

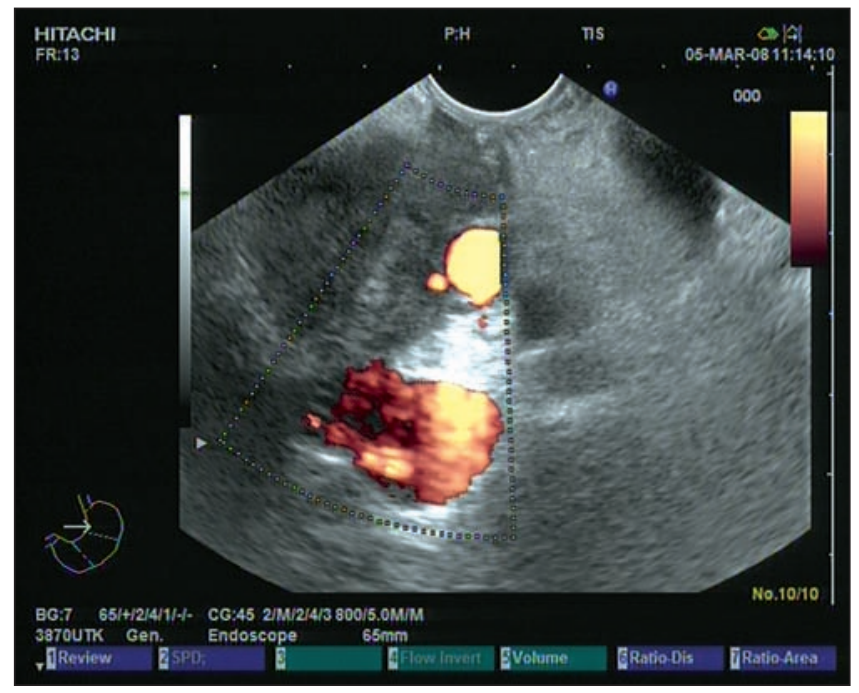

Fig. 2. This image shows the same pancreatic lesion, showing in more detail the vascular infiltration with angio-Doppler evaluation.

Imagen que muestra la misma lesión descrita, apreciándose a mayor detalle, con el estudio angio-doppler, la infiltración vascular difusa del eje porto-mesentérico.

tify enlarged lymph nodes at the celiac axis, peripancreatically, and at the liver hilium. In the endoscopic image we observed a huge deformation of the posterior duodenal wall, with an infiltrating ulcer measuring $3 \mathrm{~cm}$, with spontaneous bleeding and an adherent clot, probably related to tumor infiltration. While performing EUS we proceeded to perform a fine-needle aspiration (FNA) of the pancreatic lesion. A pathological analysis of the sample revealed the presence of an undifferentiated malignant tumor compatible with fusocellular sarcoma, with immunohistochemistry being negative for cytokeratins, c-KIT and CD34 (thus ruling out carcinoma and GIST tumor), and positive for desmine (which directed the diagnosis towards a mesenchymal sarcomatous tumor with muscular origin). The patient evolved unfavorably with a rapid progression of disease, which proved finally fatal.

\section{DISCUSSION}

EUS, a technique combining endoscopic and ultrasound images, is in continuous evolution since it was first established in the 1980s. In fact, with electronic equipment it is possible to perform a vascular analysis with the corresponding Doppler options (color-Doppler, angioDoppler and pulsated-Doppler) (9). The performance of EUS with linear devices allows guided biopsies in territories of difficult percutaneous access, like the mediastinum, perirectal region, and pancreas. These biopsies can be performed with a low rate of complications.

EUS-guided FNA is the ideal way to obtain samples from pancreatic tumors. Initial results regarding the diag- 
nostic accuracy of the technique were published in 1995 by Giovannini et al. The authors published a diagnostic accuracy of $79 \%$ (10). In the following years, these results improved, mainly due to technical optimization and the materials available, reaching a diagnostic accuracy that ranges between 72 and $96 \%$ for the detection of malignancy (11-20) (Table I).

Table I. EUS-guided FNA diagnostic accuracy in the cytohistological diagnosis of solid pancreatic tumors from the most important studies published

\begin{tabular}{lccccc}
\hline Author & Year & $n$ & Sensitivity & Specificity & Accuracy \\
\hline Giovannini (10) & 1995 & 43 & 75 & 100 & 79 \\
Bhutani (11) & 1997 & 47 & 64 & 100 & 72 \\
Gress (12) & 1997 & 121 & 80 & 100 & 86 \\
Chang (13) & 1997 & 44 & 92 & 100 & 95 \\
Faigel (14) & 1997 & 45 & 94 & 100 & 96 \\
Wiersema (15) & 1997 & 124 & 87 & 100 & 88 \\
Williams (16) & 1999 & 144 & 72 & 100 & 76 \\
Voss (17) & 2000 & 90 & 75 & 88 & 84 \\
Harewood (18) & 2002 & 184 & 94 & 71 & - \\
Raut (19) & 2003 & 233 & 91 & 100 & 92 \\
Eloubeidi (20) & 2003 & 158 & 84 & 97 & 84 \\
Iglesias-García (24) & 2007 & 62 & 84 & 100 & 90 \\
\hline
\end{tabular}

In these publications, results are obtained by cytological analysis of the material obtained mainly with the standard 22-gauge needles. Nowadays the use of tru-cut needles makes it possible to obtain material for histological analysis; however, there are still some limitations with this needle, as it can only be used through the stomach, and the transduodenal approach is difficult and entails more risks for complications. With this technique, diagnostic accuracy is similar to the one previously reported for cytology (around 80\%) (21-23), but provides the possibility to perform special analyses on the specimens (immunohistochemistry, molecular markers, DNA and RNA), which may help in the characterization of tumors different than adenocarcinoma, like lymphomas or metastatic tumors. However, with a modification of the FNA technique samples can be obtained with 22-gauge needles that are valid for histological analysis. Our group, in a study performed in 62 patients with pancreatic masses, by combining the study of classical cytology samples and the specimens obtained with the modified technique, reached an overall diagnostic accuracy of $90 \%$ in the evaluation of solid pancreatic masses. We thus detected pancreatic metastases from an oat-cell lung cancer and a pancreatic lymphoma (24).

In our case, the patient had a pancreatic tumor revealed by imaging techniques (abdominal ultrasounds and EUS), with some morphological characteristics different to those usually seen in a pancreatic adenocarcinoma but compatible with this diagnosis. It was guided biopsy the procedure that permitted to reach a diagnosis of fusocellular sarcoma of pancreatic origin. The pancreatic localization of fusocellular sarcomas is rare and corresponds to a small percentage of pancreatic tumors, with few cases published in the literature $(25,26)$. For the diagnosis of this type of tumors a immunohistochemical analysis is essential to demonstrate positivity for desmine and negativity for cytokeratins (excluding the possibility of a carcinoma), c-KIT and CD34 (which excludes a GIST tumor) (27). Although prognosis in this type of tumors is unpredictable, pancreatic sarcomas seem to be highly aggressive. In our patient, the tumor had an especially aggressive progression, and the patient died a few days after diagnosis.

The performance of EUS-guided FNA has also other important clinical implications, as it can contraindicate a surgical procedure in $41 \%$ of patients, avoid the performance of other diagnostic techniques in $57 \%$ of cases, and modify the therapeutic approach in $68 \%$ of cases (28).

However, EUS-guided FNA is not only a very useful tool, able to significantly optimize the diagnosis of solid pancreatic masses, but also has a low rate of complications associated with the technique. The risk of bacteremia is very low; the risk of acute pancreatitis ranges from 1 to $2 \%$. Other complications like bleeding or peritonitis are rare. The risk of infectious complications is particularly associated with cystic lesions, and therefore antibiotics are always recommended following pancreatic cyst aspiration (29). The largest study included 355 patients who underwent EUS-guided FNA for solid pancreatic lesions; it describes a rate of complications of only $2.5 \%$ ( 3 cases of abdominal pain, 2 of fever, and 3 episodes of mild acute pancreatitis). None of the patients experienced clinically significant hemorrhage, perforation, or death (30). The rate of tumoral seeding with EUS-guided fine-needle aspirations is significantly lower than with percutaneous fine-needle aspiration. In the paper published by Micames et al., in the EUS-guided FNA group the percentage of patients who developed peritoneal carcinomatosis was $2.2 \%$, significantly lower than in the group with percutaneous-guided FNA $(16.3 \%)(\mathrm{p}<$ 0.025) (31).

In conclusion, EUS-guided FNA has became an essential tool in the evaluation of pancreatic tumors, and can be considered the technique of choice for the diagnosis and local staging of both chronic pancreatitis and different pancreatic tumors. This method is thus considered as an essential tool for the diagnostic and therapeutic algorithms of pancreatic tumors. EUS has the capability to optimize the classification of pancreatic tumors, both from the images and histological characterization it allows. 


\section{REFERENCES}

1. Jemal A, Murray T, Ward E, Samuels A, Tiwari Rc, Ghafoor A, et al. Cancer statistics, 2005. CA Cancer J Clin 2005; 55: 10-30.

2. DiMagno EP, Reber HA, Tempero MA. AGA technical review on the epidemiology, diagnosis, and treatment of pancreatic ductal adenocarcinoma. Gastroenterology 1999; 117: 1464-84.

3. Role of endoscopic ultrasonography. American society for gastrointestinal endoscopy. Gastrointest Endosc 2000; 52(6): 852-9.

4. Byrne MF, Jowell PS. Gastrointestinal imaging: Endoscopic ultrasound. Gastroenterology 2002; 122(6): 1631-48.

5. Iglesias García J, Domínguez-Muñoz JE. Endoscopic ultrasoundguided biopsy for the evaluation of pancreatic tumors. Gastroenterol Hepatol 2007; 30(10): 597-601.

6. Eloubeidi MA, Tamhane A, Varadarajulu S, Wilcox CM. Frequency of major complications after eus-guided FNA of solid pancreatic masses: A prospective evaluation. Gastrointest Endosc 2006; 63(4): 622-9.

7. Erickson RA. EUS-guided FNA. Gastrointest Endosc 2004; 60(2): 267-79.

8. Eloubeidi MA, Varadarajulu S, Desai S, Shirley R, Heslin MJ, Mehra M, et al. A prospective evaluation of an algorithm incorporating routine preoperative endoscopic ultrasound-guided fine needle aspiration in suspected pancreatic cancer. J Gastrointest Surg 2007; 11(7): 813-9.

9. Niwa K, Hirooka Y, Niwa Y, Itoh A, Ohmiya N, Hashimoto S, et al. Comparison of image quality between electronic and mechanical radial scanning echoendoscopes in pancreatic diseases. J Gastroenterol Hepatol 2004; 19: 454-9.

10. Giovannini M, Seitz JF, Monges F, Perrier H, Rabbia I. Fine-needle aspiration cytology guided by endoscopic ultrasonography: results in 141 patients. Endoscopy 1995; 27: 171-7.

11. Bhutani MS, Hawes RH, Baron PL, Sanders-Cliette A, van Velse A, Osborne JF, et al. Endoscopic ultrasound guided fine needle aspiration of malignant pancreatic lesions. Endoscopy 1997; 29: 854-8.

12. Gress FG, Hawes RH, Savides TJ, Ikenberry SO, Lehman GA. Endoscopic ultrasound-guided fine-needle aspiration biopsy using linear array and radial scanning endosonography. Gastrointest Endosc 1997; 45: 243-50.

13. Chang KJ, Nguyen P, Erickson RA, Durbin TE, Katz KD. The clinical utility of endoscopic ultrasound-guided fine-needle aspiration in the diagnosis and staging of pancreatic carcinoma. Gastrointest Endosc 1997; 45: 387-93.

14. Faigel DO, Ginsberg GG, Bentz JS, Gupta PK, Smith DB, Kochman ML. Endoscopic ultraosound-guided real-time fine-needle aspiration biopsy of the pancreas in cancer patients with pancreatic lesions. J Clin Oncol 1997; 15: 1439-43.

15. Wiersema MJ, Vilmann P, Giovannini M, Chang KJ, Wiersema LM. Endosonography-guided fine-needle aspiration biopsy: diagnostic accuracy and complication assessment. Gastroenterology 1997; 112: 1087-95.

16. Williams DB, Sahai AV, Aabakken L, Penman ID, van Velse A, Web J. Endoscopic ultrasound guided fine needle aspiration biopsy: a large single center experience. Gut 1999; 44: 720-6.

17. Voss M, Hammel P, Molas G, Palazzo L, Dancour A, O’Toole D. Value of Endoscopic ultrasound guided fine needle aspiration biopsy in the diagnosis of solid pancreatic masses. Gut 2000; 46: 244-9.

18. Harewood GC, Wiersema MJ. Endosonography-guided fine needle aspiration biopsy in the evaluation of pancreatic masses. Am J Gastroenterol 2002; 97: 1386-91.

19. Raut CP, Grau AM, Staerkel GA, Kaw M, Tamm EP, Wolff RA. Diagnostic accuracy of endoscopic ultrasound-guided fine-needle aspiration in patients with presumed pancreatic cancer. J Gastrointest Surg 2003; 7: 118-26.

20. Eloubeidi MA, Chen VK, Eltoum IA, Jhala D, Chhieng DC, Jhala N, et al. Endoscopic ultrasound-guided fine needle aspiration biopsy of patients with suspected pancreatic cancer: diagnostic accuracy and acute and 30-days complications. Am J Gastroenterol 2003; 98(12): 2663-8.

21. Levy MJ, Jondal ML, Clain J, Wiersema MJ. Preliminary experience with an EUS-guided trucut biopsy needle compared with EUS-guided FNA. Gastrointest Endosc 2003; 57: 101-6.

22. Varadarajulu S, Fraig M, Schmulewitz N, Roberts S, Wildi S, Hawes $\mathrm{RH}$, et al. Comparison of EUS-guided 19-gauge Trucut needle biopsy with EUS-guided fine-needle aspiration. Endoscopy 2004; 36: 397-401.

23. Larghi A, Verna EC, Stavropoulos SN, Rotterdam H, Lightdale CJ, Stevens MD. EUS-guided needle biopsies in patients with solid pancreatic masses: a prospective study. Gastrointest Endosc 2004; 59: $185-90$.

24. Iglesias-García J, Dominguez-Muñoz JE, Lozano-Leon A, Abdulkader I, Lariño-Noia J, Antunez J, et al. Impact of endoscopic-ultrasound fine needle biopsy for diagnosis of pancreatic masses. World $\mathbf{J}$ Gastroenterol 2007; 13(2): 289-93.

25. Aihara H, Kawamura Y, Toyama N, Mori Y, Konishi F, Yamada S. A small leiomyosarcoma of the pancreas treated by local excision. HPB (Oxford) 2002; 4(3): 145-8.

26. Muhammad SU, Azam F, Zuzana S. Primary pancreatic leiomyosarcoma: A case report. Cases J 2008; 1(1): 280.

27. Cruz J, Navarro S, Guerra M, García R, Lima M, Molina P, et al. Value of immunohistochemistry in the typification of soft tissue sarcomas and the discordance with the conventional histopathologic diagnosis: A study of cases from INO (Cuba). Rev Esp Patol 2005; 38(3): 149-56.

28. Lambert R, Caletti G, Cho E, Chang KJ, Fusaroli P, Feussner H, et al. International workshop on the clinical impact of endoscopic ultrasound in gastroenterology. Endoscopy 2000; 32: 549-84.

29. Adler DG, Jacobson BC, Davila RE, Hirota WK, Leighton JA, Qureshi WA, et al., ASGE. ASGE guidelines: complications of EUS. Gastrointest Endosc 2005; 61: 8-12.

30. Eloubeidi MA, Tamhane A, Varadajulu S. Frequency of major complications after EUS-guided FNA of solid pancreatic masses: a prospective evaluation. Gastrointest Endosc 2006; 63: 622-9.

31. Micames C, Jowell PS, White R, Paulson E, Nelson R, Morse M, et al. Lower frequency of peritoneal carcinomatosis in patients with pancreatic cancer diagnosed by EUS-guided FNA vs percutaneous FNA. Gastrointest Endosc 2003; 58: 690-5. 